\title{
EFFECT OF DROUGHT CONDITION ON GROWTH, YIELD AND GRAIN QUALITY OF UPLAND RICE
}

\author{
Raumjit Nokkoul and Teerayut Wichitparp \\ King Mongkut's Institute of Technology Ladkrabang, Chumphon Campus, \\ Pathio, Chumphon, 86160, Thailand
}

Received 2014-04-03; Revised 2014-04-06; 2014-07-26

\begin{abstract}
Thus, the objective of this study was to investigate the effect of drought condition on growth, yield and grain quality of two varieties in upland rice: Nangdam and Lebnok. The experiment was performed at the King Mongkut's Institute of Technology Ladkrabang, Chumphon Campus, Thailand during July to November, 2010. The study was conducted in randomized complete block design with four replications. This results showed that Nangdam and Labnok varieties were got 12.40-97.10 mm of average monthly rainfall in the vegetative, reproductive and grain formation to ripening stages. Nangdam and Lebnok had days to booting of 72 and 68 Days After Germination (DAG), respectively, days to 50\% flowering of 93 and 90 DAG, respectively, which were higher than the normal average of 2 to 6 days. The two tested varieties had low grain yields of 29.12 and $26.20 \mathrm{~kg} / \mathrm{ha}$, respectively, when they were grown at the low level rainfall. All varieties had higher number of empty grain of 48 and 33 grain per panicle, respectively, number of low perfect grains of 53 and 57 grain per panicle, respectively, number of imperfect grains of 35 and 30 grain per panicle, respectively, chalky grains of 17.50 and $15.20 \%$, respectively and breaking grains of 0.75 and $2.50 \%$, respectively. However, there were no significant different among those traits between the two varieties. The two varieties of upland rice had smaller grain which was lower than the standard.
\end{abstract}

Keywords: Climate Change, Growth, Yield and Grain Quality, Upland Rice, Thailand

\section{INTRODUCTION}

Upland rice (Oryza sativa L.) is cultivated on nearly 20 million ha in different countries of the world. It had growing area about $60 \%$ in Asia, $30 \%$ in Latin America and $10 \%$ in Africa. More than $50 \%$ of Asia upland rice is grown in south Asia (Hari et al., 1994). In Thailand, most upland rice is grown in the northern and Southern, where have growing area of upland rice about $10 \%$ of total rice growing areas. It has been grown almost exclusively by small-household food security. In Southern part of Thailand, upland rice is cultivated as rainfed rice under upland conditions, which were received $200 \mathrm{~mm}$ of average monthly rainfall. But during the rainy season, the rainfall have less than $1 \mathrm{~mm}$ per day with more than 15 consecutive days. It affects to rice growth and reduces grain yield and quality (Nokkoul and Wichitparp, 2013a). Drought condition is a serious problems for rice production in many regions of the world. In rice the effect of drought varies with the variety, degree and duration of stress and growth stages (Sikuku et al., 2010). When drought condition occurred during vegetative, reproductive and grain formation stages, it had decreased in yield of up to $30 \%$ was due to reduced panicle number per unit area, when drought occurred during panicle development. Anthesis was delayed, the number of spikelets per panicle was reduced to $60 \%$ and when drought occurred during grain filling, the percentage of filled grains decreased to $40 \%$ and individual grain mass decreased by $20 \%$ (Boonjung and Corresponding Author: Raumjit Nokkoul, King Mongkut's Institute of Technology Ladkrabang, Chumphon Campus, Pathio, Chumphon, 86160, Thailand 
Fukai, 1996). These factors are the principal problem for upland rice production in Southern Thailand. Thus, the objective of this study was to investigate the effect of drought condition on growth, yield and grain quality of upland rice two varieties produced in Chumphon province of Southern Thailand.

\section{MATERAILS AND METHODS}

This study was conducted at King Mongkut's Institute of Technology Ladkrabang, Chumphon Campus, Thailand (Latitude $10^{\circ} 00^{\prime} 30.05^{\prime \prime} \mathrm{N}$ Longitude 99 25 ' 45” E Altitude $17.84 \mathrm{~m}$ above the sea level) from July to November, 2010. Two varieties of upland rice: Nangdam and Lebnok seeds were produced during the rainy season. The land was ploughed and disc harrowed and leveled before sowing the seeds. Four seeds of upland rice were sown per hole with spacing of $30 \mathrm{~cm}$ within rows and $30 \mathrm{~cm}$ between rows. The plants were thinned to three plants per hole after 14 DAG. The total area of each plot was $10 \mathrm{~m}^{2}$. The fertilizer $(15 \mathrm{~N}-15 \mathrm{P}-15 \mathrm{~K})$ was applied twice at 25 and 45 DAG. Weeds were eliminated by using hoes twice at the age of 20 and 40 DAG. Harvesting was done when the all grain maturity. The collected data were plant high, days to booting, days to $50 \%$ flowering, days to harvesting of the grain, number of panicle per tiller, panicle length, grain yield, number of grains per panicle, number of perfect grains, number of empty grains, number of imperfect grains, number of green grains, chalky grain, breaking grain, grain size and 1,000 grain weight. After threshing, the grains were sun-day, sieved and weighted after the measurement of the moisture content. The grain yields were determined for corresponding weight of standard moisture of $14 \%$. Each test was done with four replications. Average of daily rainfall, minimum and maximum temperatures from July to November, 2010 was received from the Tha Ta Pao Agrometeorological Station, Muang Chumphon, Chumphon, Thailand. All data were analyzed using the analysis of variance and means separated by Duncan's Multiple Range Test (DMRT) at the $5 \%$ level of significance.

\section{RESULTS}

\subsection{Environmental Data}

Effects of number of rainy days, rainfall, maximum and minimum temperatures on grain production of upland rice (Nangdam and Lebnok varieties) grown during the rainy season (Fig. 1). The results showed that the rainfall during the July to November, 2010 was found to be deleterious for upland rice growth, yield and grain quality. In vegetative, reproductive and grain formation to ripening stages of rice plants received average monthly rainfall ranges from 12.40 to $97.10 \mathrm{~mm}$ (Fig. 1a) with average monthly temperatures ranges from 31.40 to $35.00^{\circ} \mathrm{C}$ (Fig. 1b). The two tested varieties got 12.40-59.20 $\mathrm{mm}$ of rainfall during vegetative stage, $57.40 \mathrm{~mm}$ in reproductive stage, $97.10 \mathrm{~mm}$ in grain formation stage, with number of 10, 7 and 12 raining days, respectively.

\subsection{Growth Responses}

Effect of drought condition on growth of Nangdam and Lebnok varieties are presented in Fig. 2a. The Nangdam was the plant high of $95.50 \mathrm{~cm}$, days to booting of 72 days, days to $50 \%$ flowering of 93 days and days to harvesting of the grain of 122 days, but not significantly different from those of Lebnok was the plant high of $92 \mathrm{~cm}$, days to booting of 68 days, days to $50 \%$ flowering of 90 days and days to harvesting of 120 days. The number of panicle per tiller was affected by drought condition. There was no significant difference in number of panicle per tiller among the varieties had resembled number of panicle per tiller of 4 panicle. All varieties had similar panicle length ranges from 24.22 to $24.45 \mathrm{~cm}$.

\subsection{Grain Yield Responses}

The yield at $14 \%$ moisture content of the Nangdam variety had the grain yield of $29.12 \mathrm{~kg} / \mathrm{ha}$, which was not significantly different from those of Lebnok variety which gave the grain yield of $26.20 \mathrm{~kg} / \mathrm{ha}$. The grain per panicle was not significantly different among the varieties. The Nangdam and Lebnok varieties had the grain per panicle of 161.00 and 146.00 grain, respectively. Both varieties of upland rice had the highest number of empty grain of 48.00 and 33.00 grain per panicle, respectively (Fig. 2b), number of low perfect grain of 53.00 and 57.00 grain respectively, number of high imperfect grain of 35.00 and 30.00 grain per panicle, respectively. percentage of high chalky grain of 17.50 and $15.20 \%$, respectively and breaking grain of 0.75 and $2.50 \%$, respectively, which were not significantly different among the varieties (Fig. 3a).

Grain sizes (Fig. 3b) of the two varieties were measured in width, length and thick. It was found that Nangdam and Lebnok varieties were not significantly different among the varieties. Nangdam and Lebnok varieties had grain width, length and thick of 1.07 and $0.97,2.48$ and 2.01 and 1.87 and $1.75 \mathrm{~mm}$, respectively. As for the 1,000 grain weight (Fig. 3b), Nangdam and Lebnok varieties had 1,000 grains weight of 18.91 and $18.67 \mathrm{~g}$, respectively, which were not significantly different among the varieties. 


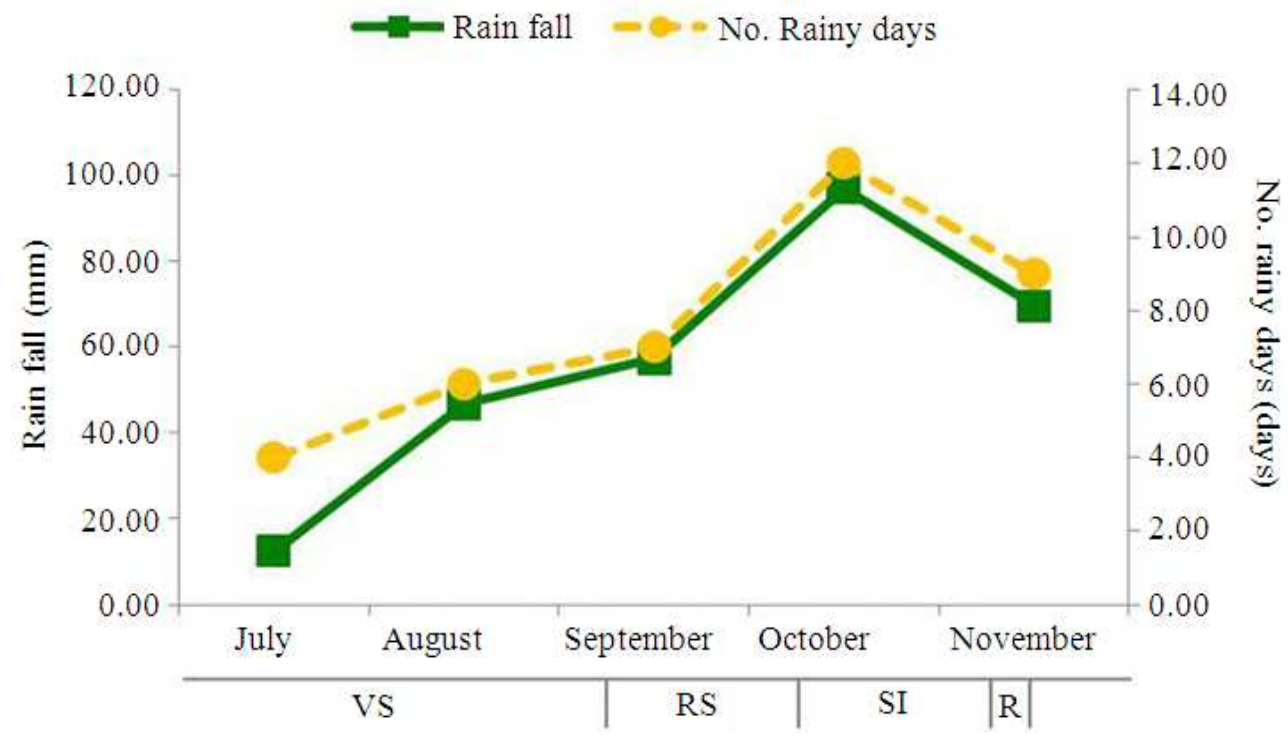

$\mathrm{VS}=$ Vegetative Stage, $\mathrm{RS}=$ Reproductive Stage, $\mathrm{SI}=$ Seed Information, $\mathrm{R}=$ Ripening

(a)

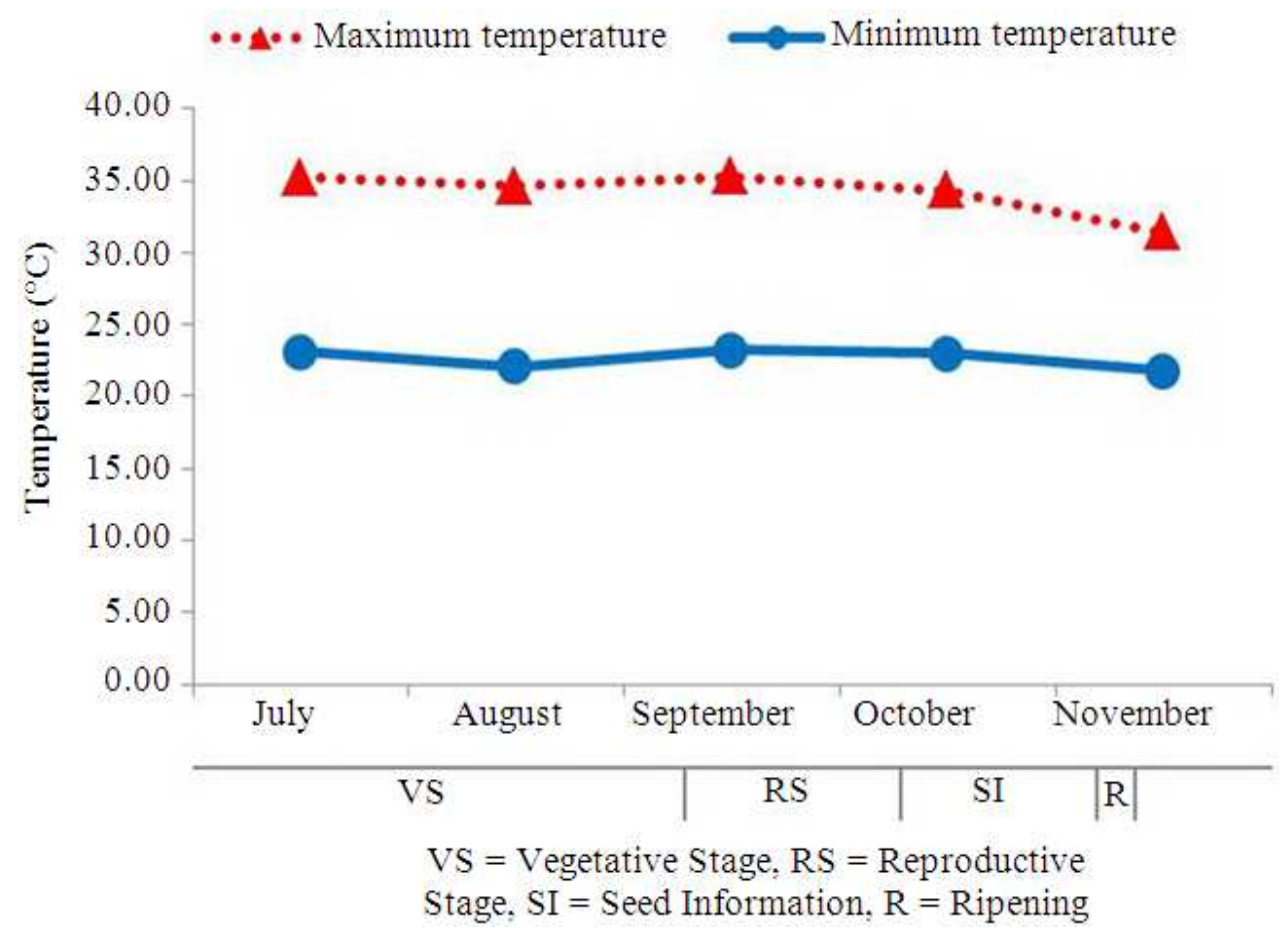

(b)

Fig. 1. Data of amount of monthly rainfall and number of rainy days (a), minimum and maximum temperatures (b) in the experiment location, King Mongkut's Institute of Technology Ladkrabang, Chumphon Campus, Thailand during July to November 2010 


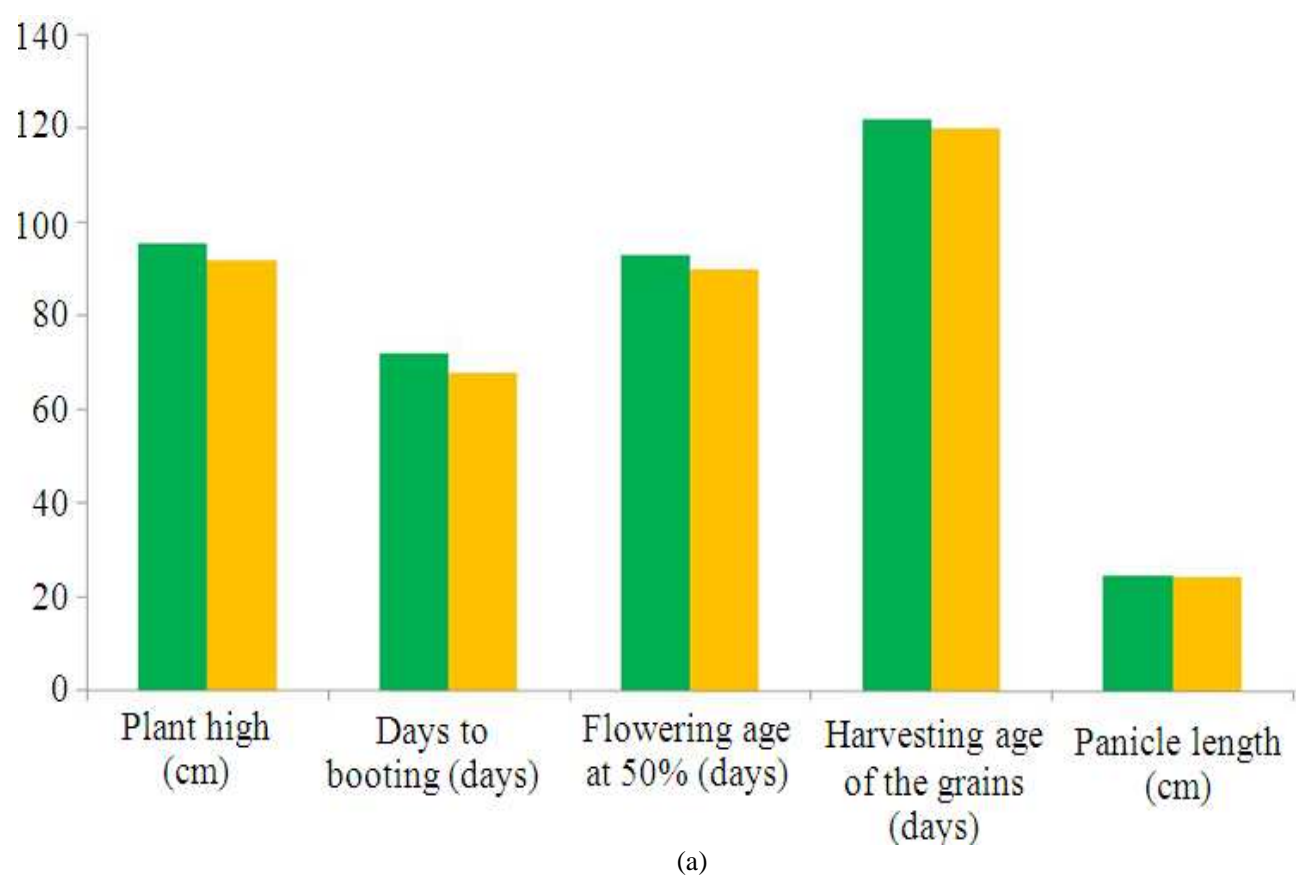

(a)

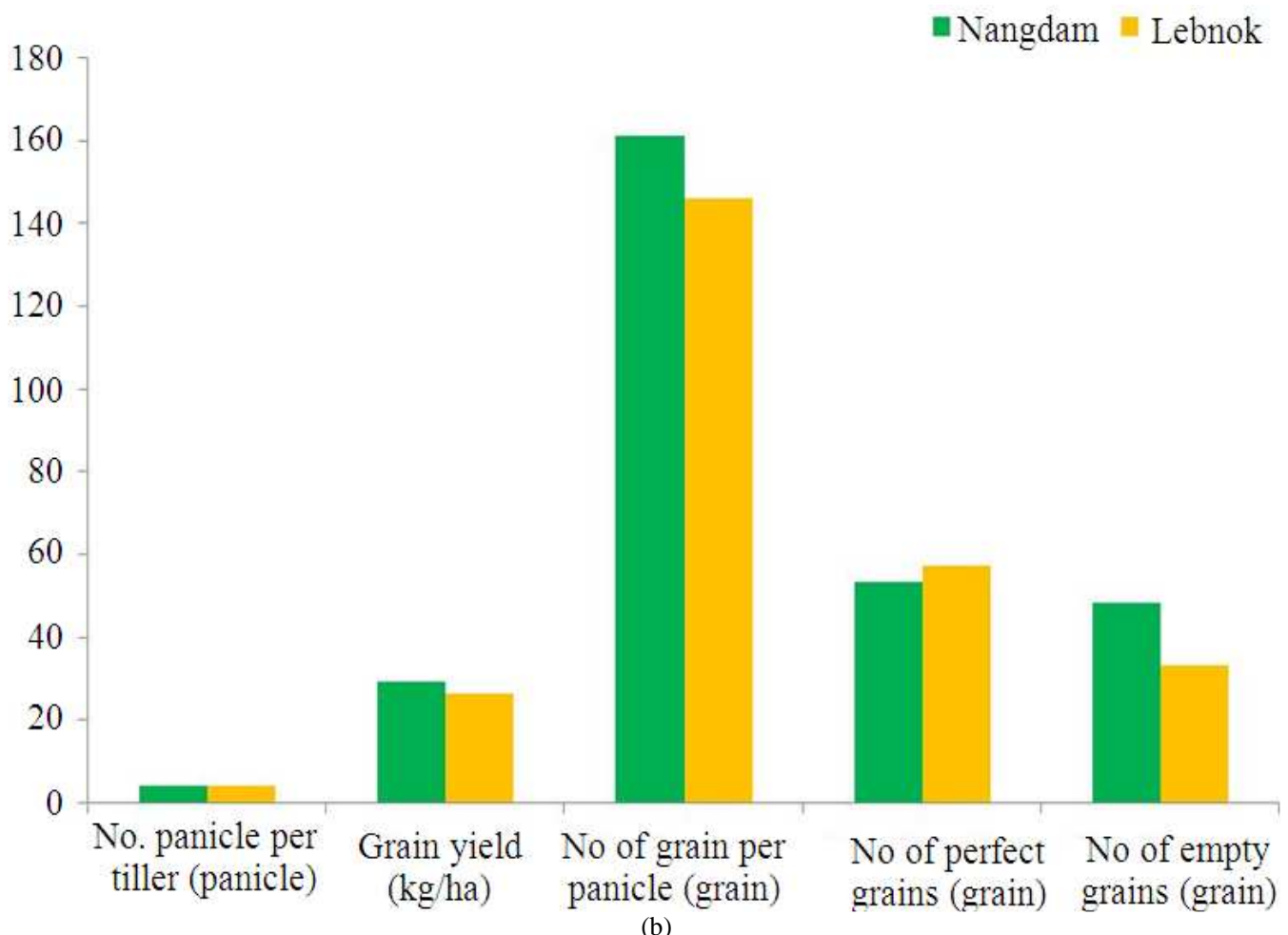

Fig. 2. Plant high, days to booting, flowering age at 50\%, harvesting age of the grains, panicle length (a), number of panicle per tiller, grain yield, number of grain per panicle, number of perfect grains and number of empty grains (b) of upland rice 


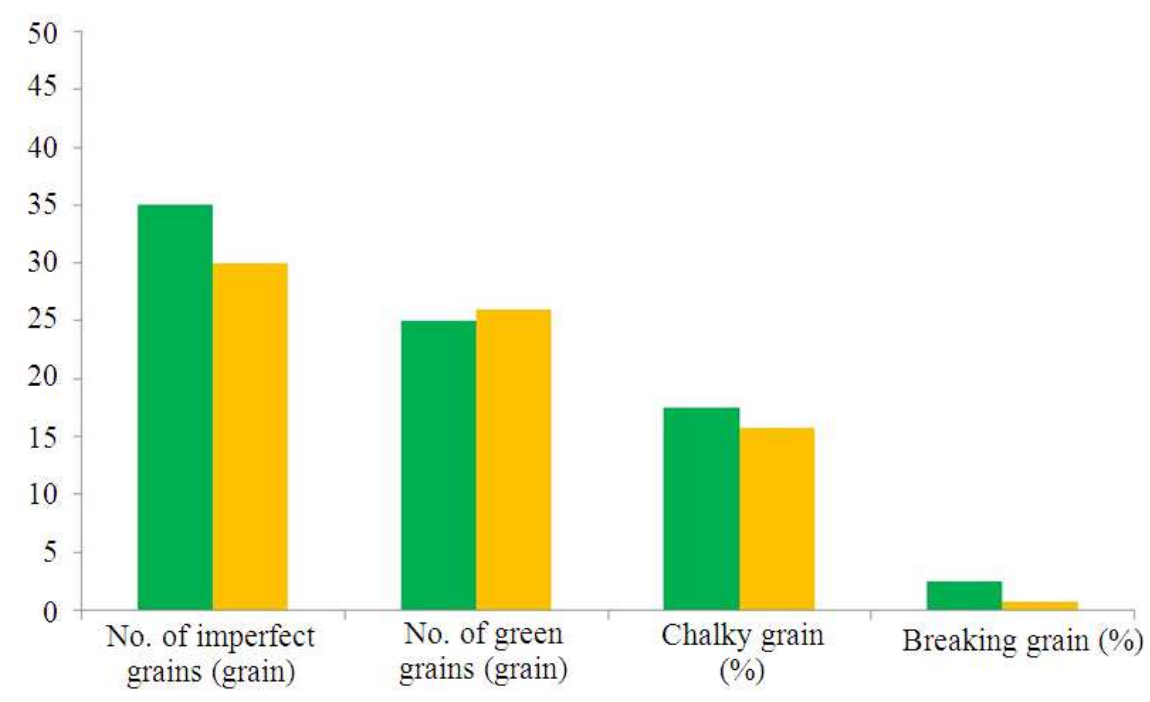

(a)

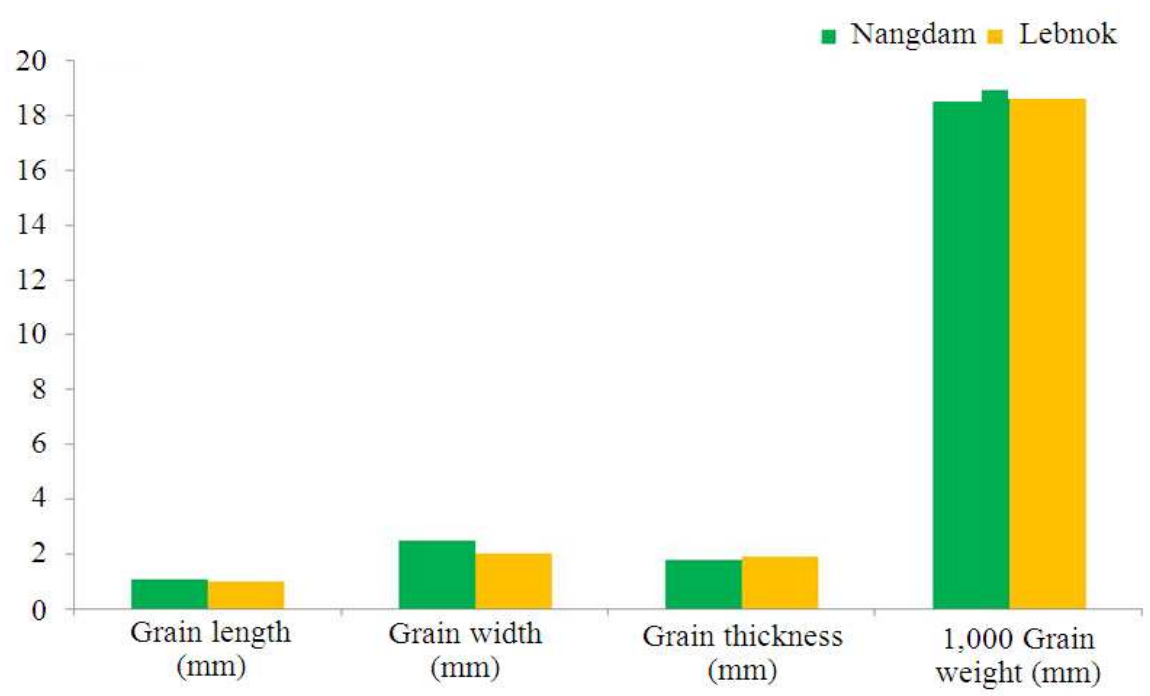

(b)

Fig. 3. Number of imperfect grains, number of green grains, chalky grain, breaking grain (a), grain size and 1,000 grain weight (b) of upland rice

\section{DISCUSSION}

The study on effect of drought condition on growth, yield and grain quality two varieties of upland rice; Nangdam and Lebnok. When drought condition occurred during vegetative stage, the upland rice plants received less rainfall, not appropriated distribution of rainfall and no rainfall for 20 days continuously (Fig. 1a), these would cause seriously slow down of plant growth, it reduces plant heights and number of panicle per tiller (Fig. 2a). Sikuku et al. (2010) reported that drought before or during tillering reduced the number of tillers. The Nangdam and Lebnok can advance flowering by up to 2-6 days (Fig. 2a) with corresponding. Similar results were reported by (Levitt, 1980) wheat exposed to mild water deficit can advance flowering by up to one week because flower has an important role in drought avoidance (Fukai et al., 
1999). When drought condition occurred during reproductive to grain formation stages, both varieties of upland rice had grains within the panicles were not ripening at the same time, this would cause on the lower grain yield (26.00-29.12 kg/ha), number of low grains per panicle (146.00-161.00 grains per panicle), number of high empty grains (33.00-48.00 grains per panicle) and number of perfect grain per panicle lower than 80 grains (Fig. 2B). Similar results were reported by (Nokkoul and Wijitparp 2013b) when they were grown Lebmeunang, Kemhern and Hammuang varieties at the low level monthly rainfall between 12.40-97.10 $\mathrm{mm}$ during vegetative to ripening stages. All varieties had the high empty and had low perfect seeds per panicle and seed yields. In addition, when drought condition occurred during vegetative and reproductive stages, it decreased in yield of up to $30 \%$ was due to reduced panicle number per unit area, when drought occurred during panicle development. Anthesis was delayed, the number of spikelets per panicle was reduced of $60 \%$ and when drought occurred during grain filling: The percentage of filled grains decreased of $40 \%$ (Boonjung and Fukai, 1996). Drought condition that cause lack of rain, specifically during the grain formation to ripening stages, it affects percentage of high chalky grain (15.20-17.50) and high broken grains $(0.75-2.50 \%)$ of upland rice two varieties, it are an undesirable characteristic, since it decreases grain quality and economic value and also leads to a reduction of the milling yield (Crusciol et al., 2008).

\section{CONCLUSION}

This study investigated the effect of drought condition on growth, yield and grain quality of upland rice two varieties; Nangdam and Lebnok. The results showed that Nangdam and Labnok varieties were got 12.40-97.10 $\mathrm{mm}$ of average monthly rainfall, 34.30$35.30^{\circ} \mathrm{C}$ of average monthly temperature in the vegetative, reproductive and grain formation to ripening stages. These effects could reduce the plant height, grain yield and quality. However, the cause of declining upland rice grains yield and quality is a complex issue and is most likely a combination of a number of factors rather than any single factor. Certainly, further research is needed to fully understand these factors and interactions between them. But it is clear that the long-term productivity of upland rice in Thailand cannot be sustained. We can recommend that should be screening local upland rice cultivars for drought avoidance; select varieties with a relatively deep root system or sprinkler irrigation in the drought period are necessary for sustainable production.

\section{ACKNOWLEDGMENT}

The researchers would like to thank The Department of Agricultural Technology, King Mongkut's Institute of Technology Ladkrabang, Chumphon Campus, Pathio, Chumphon, Thailand for supporting experimental equipment and the field that the local upland rice was planted in.

\section{REFFERENCES}

Boonjung, H. and S. Fukai, 1996. Effects of soil water deficit at different growth stages on rice growth and yield under upland conditions 2. Phenology, biomass production and yield. Field Crop Res., 48: 47-55. DOI: 10.1016/0378-4290(96)00039-1

Crusciol, C.A.C., O. Arf, R.P. Soratto and G.P. Mateus, 2008. Grain quality of upland rice cultivars in response to cropping systems in the Brazilian tropical savanna. Sci. Agric., 65: 468-473. DOI: 10.1590/S0103-90162008000500004

Fukai, S., G. Pantuwan, B. Jongdee and M. Cooper, 1999. Screening for drought resistance in rainfed lowland rice. Field Crop Res., 64: 61-74. DOI: 10.1016/S0378-4290(99)00051-9

Hari, K.P., D.V. Tran and T. Ton-that, 1994. Improved Upland Rice Farming System. 1st Edn., Food and Agricultural Organization of the United Nations, Rome, ISBN-10: 925103317X, pp: 117.

Levitt, J.J., 1980. Responses of Plants to Environmental Stresses, Radiation, Salt and other Stresses. 2nd Edn,. Academic Press, New York, ISBN-10: 0124455018, pp: 365-488.

Nokkoul, R. and T. Wichitparp, 2013a. Quality of upland rice seed produced during the rainy season in Southern Thailand. Int. J. Plant, Anim. Environ. Sci., 3: 181-184.

Nokkoul, R. and T. Wichitparp, 2013b. Effects of rainfall on yield and seed quality of three local upland rice varieties produced under organic farming system. Res. J. Environ. Earth Sci., 5: 462-465.

Sikuku, P.A., G.W. Netondo, D.M. Musyimi and J.C. Onyango, 2010. Effects of water deficit on days to maturity and yield of three nerica rainfed rice varieties. ARPN J. Agric. Biol. Sci., 5: 1-9.

AJABS 